\begin{tabular}{|c|c|c|}
\hline \multirow{3}{*}{$\begin{array}{r}\text { Case Reports in } \\
\text { Gastroenterology }\end{array}$} & \multirow{2}{*}{\multicolumn{2}{|c|}{ Case Rep Gastroenterol 2020;14:178-185 }} \\
\hline & & \\
\hline & $\begin{array}{l}\text { DOI: } 10.1159 / 000506931 \\
\text { Published online: April 17, } 2020\end{array}$ & $\begin{array}{l}\text { (c) } 2020 \text { The Author(s) } \\
\text { Published by S. Karger AG, Basel } \\
\text { www.karger.com/crg }\end{array}$ \\
\hline & $\begin{array}{l}\text { This article is licensed under } t \\
\text { International License (CC BY-N } \\
\text { Usage and distribution for comm }\end{array}$ & $\begin{array}{l}\text { nons Attribution-NonCommercial } 4.0 \\
\text { ger.com/Services/OpenAccessLicense). } \\
\text { uires written permission. }\end{array}$ \\
\hline
\end{tabular}

\title{
Oropharyngeal Candidiasis as a Presenting Symptom of Crohn's Disease
}

\author{
Muhammad Sharif ${ }^{a} \quad$ Muhammad Umar Saddique $^{a} \quad$ Muhammad Zahid $^{a}$ \\ Dawlat Khan $^{\mathrm{a}}$ Tabinda Bashir $^{\mathrm{b}} \quad$ Khaled Murshed $^{\mathrm{c}}$ \\ aDepartment of Internal Medicine, Hamad General Hospital, Hamad Medical Corporation \\ Qatar, Doha, Qatar; bPrimary Health Care Corporation, Government of Qatar, Doha, Qatar; \\ 'Department of Pathology, Hamad General Hospital, Hamad Medical Corporation Qatar, \\ Doha, Qatar
}

\section{Keywords}

Inflammatory bowel disease $\cdot$ Crohn's disease $\cdot$ Oral thrush

\begin{abstract}
Oropharyngeal candidiasis is a common condition in immunosuppressed patients. Inflammatory bowel disease (IBD) is a prevalent medical condition which commonly presents with intestinal and extra intestinal manifestations. Crohn's disease (CD) tends to present more with extraintestinal symptoms. Here, we report the case of a 22 -year-old male who presented with oropharyngeal candidiasis and weight loss without abdominal symptoms, and a negative HIV serology. After a through diagnostic workup, he was found to have CD. Under CD treatment, his symptoms improved.

\author{
(C) 2020 The Author(s) \\ Published by S. Karger AG, Basel
}

\section{Introduction}

The burden of inflammatory bowel disease (IBD) is increasing globally [1]. Crohn's disease (CD) is a common gastrointestinal disorder with formidable diagnostic challenge to physicians, especially if the first presentation is an extraintestinal manifestation. Of the many extraintestinal manifestations, oropharyngeal candidiasis is not yet reported in the literature as 
a presenting complaint of $\mathrm{CD}$. Oropharyngeal candidiasis is frequently seen after a few days of anti-TNF or other immune modulating treatment. Besides, later with progression of IBD, fungal infections are more common in CD as compared to ulcerative colitis [2]. We report the case of a 22-year-old male who presented with oropharyngeal and nasal septum candidiasis and significant weight loss and who was diagnosed with CD. After starting treatment with mesalazine and prednisolone, he improved. This rare presentation of $\mathrm{CD}$ must be considered by the clinicians.

\section{Case Presentation}

We report the case of a 22-year-old Qatari male presenting with severe oropharyngeal and nasal septum candidiasis and significant weight loss without any associated abdominal symptoms.

He was admitted to Hamad General Hospital (HGH), tertiary care hospital in Doha, Qatar, from a private medical facility following upper gastrointestinal endoscopy (OGD). His chief complaint was moderate to severe odynophagia. OGD confirmed white plaques involving the oropharyngeal cavity. Endoscopic examination of the esophagus and stomach was normal, but the duodenum had features suggestive of erosive duodenitis. A clinical diagnosis of oral candidiasis and duodenitis with no obvious underlying cause was made, and the patient was transferred to HGH for further workup. Detailed history revealed a 4-week history of worsening odynophagia mainly for solids which progressed to fluids in the last 10 days requiring medical attention and hospitalization. He also reported unintentional weight loss of $12 \mathrm{~kg}$ over a period of 1 month. There were no associated abdominal symptoms including change in bowel habit, bleeding per rectum, diarrhea or vomiting, mouth or genital ulcers, joint pains or skin rash or ulcers. The patient gave no history of unsafe sexual contact or previous blood transfusion. He denied use of any medications including inhalers in the last few weeks. His past medical history was unremarkable except for an appendectomy in 2017. He did not smoke or drink alcohol. He denied any drug abuse. The patient is a student at an aviation college. On physical examination he was afebrile, had no palpable lymphadenopathy, jaundice or skin rash. His weight on admission was recorded at $61 \mathrm{~kg}$ with BMI of $20.9 \mathrm{~kg} / \mathrm{m}^{2}$. Oral cavity examination was consistent with severe oropharyngeal candidiasis (Fig. 1). Systemic examination was unremarkable. He underwent nasopharyngoscopy which confirmed tongue findings as of OGD but also found patch of thrush on the anterior nasal septum (Fig. 2).

His baseline investigations, including complete blood counts, liver and renal function test, $\mathrm{B} 12$, folate, and iron studies, thyroid function tests, and protein electrophoresis, were all normal. Autoimmune workup, including ANA, ANCA, C3, C4, and immunoglobulin levels came back negative. Chest X-ray was reported normal. C-reactive protein was mildly elevated with a value of $27.7 \mathrm{mg} / \mathrm{L}(0-5 \mathrm{mg} / \mathrm{L})$. Viral panels, including hepatitis $\mathrm{B}$, hepatitis $\mathrm{C}$ and human immune deficiency virus serology, were negative.

He was commenced on topical nystatin and a proton pump Inhibitor (PPI), but only partial improvement was noted in his clinical state after 3 days of treatment. Intravenous fluconazole was commenced as odynophagia persisted.

Due to his significant weight loss and significant oropharyngeal candidiasis, a computed tomography (CT) of the thorax, abdomen, and pelvis was arranged. CT scan showed terminal ilium and ilio-cecal (IC) valve thickening, mucosal hyperenhancement, vascular engorgement, and surrounding fat stranding with adjacent subcentimetric lymph nodes (Fig. 3). 
Given the CT findings, repeat upper GI endoscopy and lower GI endoscopy were arranged. OGD showed white heavily coated tongue which could not be easily scrapped off by endoscope (Fig. 4). Stomach and esophagus examinations were unremarkable, and there was mild duodenitis but no erosions.

Colonoscopy findings were multiple deep ulcers with erythematous and friable mucosa of terminal ileum and diseased IC valve with some ulcers (Fig. 5). Ascending and transverse colon was normal. However, the descending colon showed multiple tiny aphthous ulcers at the recto-sigmoid junction (Fig. 6).

Biopsy from the ilium and IC valve suggested moderate to severe chronic active inflammation with granulation tissue (Fig. 7). No granuloma, dysplasia, or malignant changes were noted. Cytomegalovirus immunostaining (CMV) was negative. The rest of the histopathology from the esophagus, ascending, transverse, descending colon, and rectosigmoid junction were normal. The diagnosis of CD was made based on colonoscopy, CT of the abdomen, and histopathology findings.

He complained of colicky abdominal pain on the tenth day post admission to our hospital. He had no associated diarrhea or change in his usual bowel habit. He was commenced on mesalazine $2,000 \mathrm{mg}$ daily. As his symptoms improved, the patient was discharged with outpatient (OPD), follow-up was arranged in the gastroenterology (GI) clinic. With mesalazine, he showed partial improvement of his symptoms of odynophagia and abdominal discomfort. MRI enteroclysis was also arranged as OPD which showed active disease (Fig. 8). On his second outpatient visit, prednisolone $40 \mathrm{mg}$ was also added. With a combination of steroids and mesalazine, his symptoms improved significantly. He is currently being followed up in OPD by the GI team, a dietitian and an IBD specialist nurse. His weight on the latest follow-up has increased to $64 \mathrm{~kg}$.

\section{Discussion}

Oropharyngeal thrush is a relatively common medical illness due to candidal infection. It is commonly seen in adults who have had a recent use of antibiotics, oral steroids or inhaled form, denture use, and in immunocompromised patients [3].

In IBD patients, candidal infections predominantly involve the respiratory or gastrointestinal tract and rarely cause candidemia. Typical symptoms of IBD include altered bowel habit with loose stools with or without blood and mucus. Patients with CD may present with abdominal right lower quadrant pain, perianal fistula or abscess, in addition to general fatigue, malaise, nausea, and weight loss.

Extraintestinal manifestations (EIM) are common in patients with CD. Musculoskeletal, liver, skin, and eye involvement as a presenting EIM symptom of CD is not uncommon and may represent one third of the CD patients [4]. Erythroderma nodosum, pyoderma gangrenosum, and stomatitis are the most common dermatological EIM of IBD [5].

Oropharyngeal candidiasis as a presenting complaint of IBD is unknown. Usually in patients with known IBD, oropharyngeal candidiasis is secondary to the use of anti-TNF, steroids, or other immunosuppressant agents $[6,7]$.

Candida albicans is the most common type of fungal infection in patients suffering from $\mathrm{CD}$, rarely it is caused by Candida tropicalis or Candida glabrata [8]. Although the most common type of fungal infection affecting IBD patients is Candida, other opportunistic infections, including histoplasmosis or Pneumocystis jirovecii, can affect this group of patients within days to months of initiation of immunosuppressants [9]. 
There is a potential link between CD and the gut's microbial flora. C. albicans is a normal commensal of the GI tract but interestingly, CD patients are often heavily colonized with this specie as compared to the healthy individuals [10]. There may be a link between inflammatory response to $C$. albicans and the development and/or progression of CD in murine models of $\mathrm{CD}[11]$.

The treatment of oropharyngeal candidiasis is local and or systemic. Fluconazole is more effective than other local antifungal therapies [12]. Among the systemic azole therapies, again fluconazole has a better cure rate [13].

This case highlights the need to consider the possibility of CD in patients presenting with oropharyngeal thrush with no obvious risk factors and unintentional weight loss.

\section{Acknowledgment}

The authors acknowledge the support of the Department of Radiology of Hamad General Hospital for their help with this case report.

\section{Statement of Ethics}

Written informed consent has been obtained from the patient for publication of this case report and any accompanying images. The institutional review board of the Medical Research Council of the Hamad Medical Corporation Qatar reviewed the protocol and approved it under the condition that no personal identifying information be mentioned within the publication. The approval copy can be submitted upon request.

\section{Disclosure Statement}

The authors have no potential conflicts of interest to disclose related to the publication of this case report.

\section{Funding Sources}

Qatar National Library (QNL) Doha, Qatar, is sponsor for publication charges.

\section{Author Contributions}

M.S. and M.U.S. conceived and designed the idea, literature review, data collection, wrote the manuscript, and organized the overall case report. M.Z. helped with the literature review, proofreading, and mentorship. D.K. and T.B. helped with the radiology-related literature review and radiology figures. K.M. contributed to the pathology section of the case report and the related literature review. 
Sharif et al.: Oropharyngeal Candidiasis as a Presenting Symptom of Crohn's Disease

\section{References}

1 Ng SC, Shi HY, Hamidi N, Underwood FE, Tang W, Benchimol EI, et al. Worldwide incidence and prevalence of inflammatory bowel disease in the 21st century: a systematic review of population-based studies. Lancet. 2018 Dec;390(10114):2769-78.

2 Toruner M, Loftus EV Jr, Harmsen WS, Zinsmeister AR, Orenstein R, Sandborn WJ, et al. Risk factors for opportunistic infections in patients with inflammatory bowel disease. Gastroenterology. 2008 Apr;134(4):929-36.

3 Sangeorzan JA, Bradley SF, He X, Zarins LT, Ridenour GL, Tiballi RN, et al. Epidemiology of oral candidiasis in HIV-infected patients: colonization, infection, treatment, and emergence of fluconazole resistance. Am J Med. 1994 Oct;97(4):339-46.

4 Aghazadeh R, Zali MR, Bahari A, Amin K, Ghahghaie F, Firouzi F. Inflammatory bowel disease in Iran: a review of 457 cases. J Gastroenterol Hepatol. 2005 Nov;20(11):1691-5.

5 Tavarela Veloso F. Review article: skin complications associated with inflammatory bowel disease. Aliment Pharmacol Ther. 2004 Oct;20(s4 Suppl 4):50-3.

6 Lichtenstein GR, Feagan BG, Cohen RD, Salzberg BA, Diamond RH, Price S, et al. Serious infection and mortality in patients with Crohn's disease: more than 5 years of follow-up in the TREAT ${ }^{\text {TM }}$ registry. Am J Gastroenterol. 2012 Sep;107(9):1409-22.

7 Deepak P, Stobaugh DJ, Ehrenpreis ED. Infectious complications of TNF- $\alpha$ inhibitor monotherapy versus combination therapy with immunomodulators in inflammatory bowel disease: analysis of the Food and Drug Administration Adverse Event Reporting System. J Gastrointestin Liver Dis. 2013 Sep;22(3):269-76.

8 Ali T, Kaitha S, Mahmood S, Ftesi A, Stone J, Bronze MS. Clinical use of anti-TNF therapy and increased risk of infections. Drug Healthc Patient Saf. 2013;5:79-99.

9 Lee JH, Slifman NR, Gershon SK, Edwards ET, Schwieterman WD, Siegel JN, et al. Life-threatening histoplasmosis complicating immunotherapy with tumor necrosis factor $\alpha$ antagonists infliximab and etanercept. Arthritis Rheum. 2002 Oct;46(10):2565-70.

10 Standaert-Vitse A, Sendid B, Joossens M, François N, Vandewalle-El Khoury P, Branche J, et al. Candida albicans colonization and ASCA in familial Crohn's disease. Am J Gastroenterol. 2009 Jul;104(7):1745-53.

11 Jawhara S, Thuru X, Standaert-Vitse A, Jouault T, Mordon S, Sendid B, et al. Colonization of mice by Candida albicans is promoted by chemically induced colitis and augments inflammatory responses through galectin3. J Infect Dis. 2008 Apr;197(7):972-80.

12 Finlay PM, Richardson MD, Robertson AG. A comparative study of the efficacy of fluconazole and amphotericin $B$ in the treatment of oropharyngeal candidosis in patients undergoing radiotherapy for head and neck tumours. Br J Oral Maxillofac Surg. 1996 Feb;34(1):23-5.

13 Oude Lashof AM, De Bock R, Herbrecht R, de Pauw BE, Krcmery V, Aoun M, et al.; EORTC Invasive Fungal Infections Group. An open multicentre comparative study of the efficacy, safety and tolerance of fluconazole and itraconazole in the treatment of cancer patients with oropharyngeal candidiasis. Eur J Cancer. 2004 Jun;40(9):1314-9.

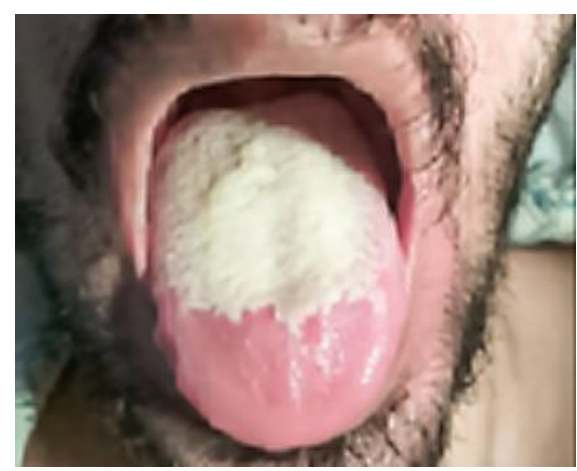

Fig. 1. Oropharyngeal thrush. 


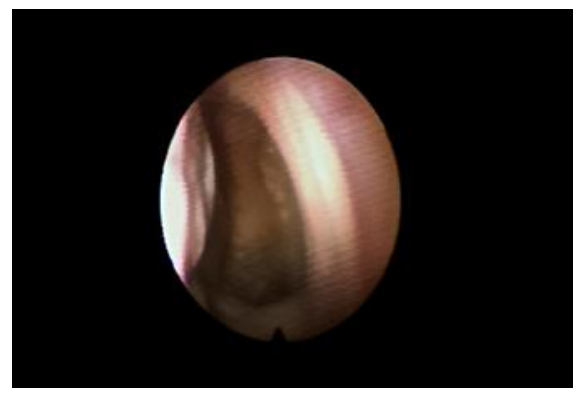

Fig. 2. Nasopharyngoscopy showed patch of thrush on the anterior nasal septum.

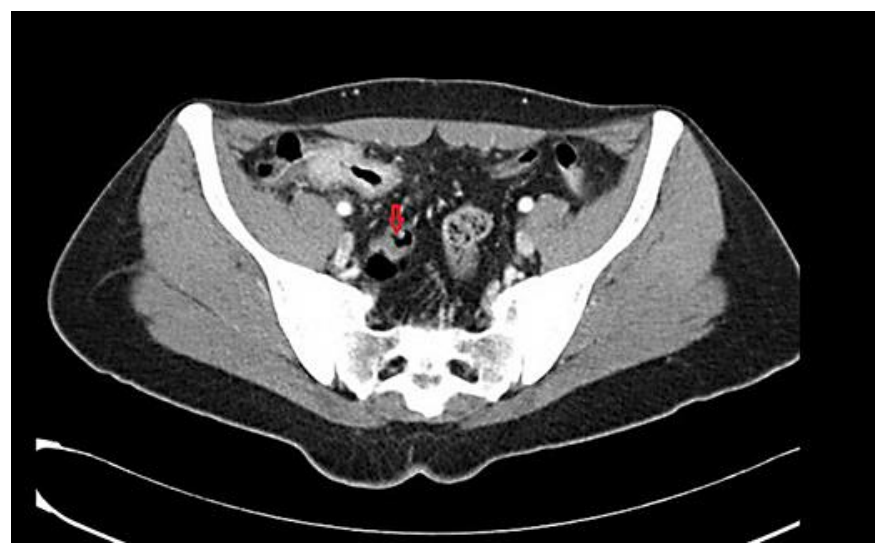

Fig. 3. CT of the abdomen with contrast revealing terminal ilium and ileo-cecal valve thickening (arrow), mucosal hyperenhancement, and vascular engorgement.

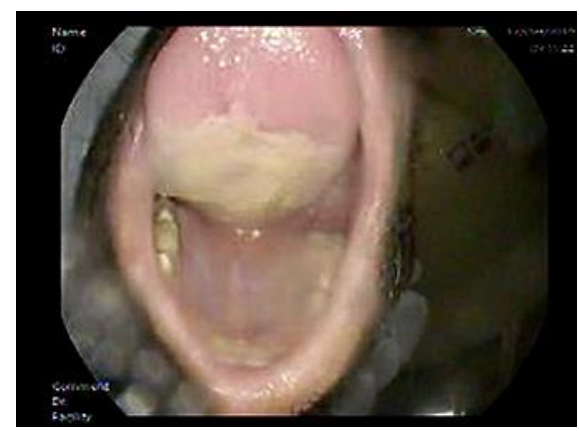

Fig. 4. Upper GI endoscopy showing a heavily white coated tongue which could not be easily scrapped off by endoscope. 


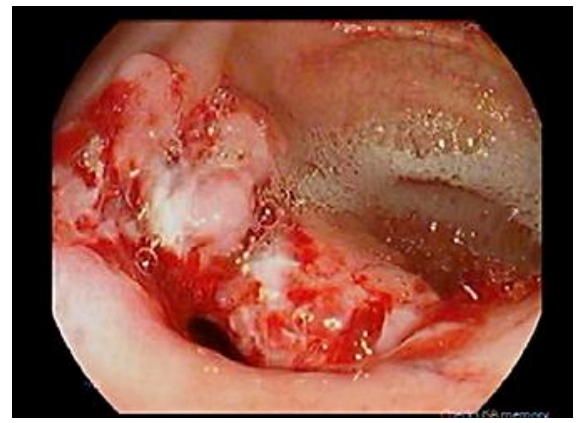

Fig. 5. Colonoscopy showing friable mucosa of terminal ileum and IC (ileo-cecal) valve with some ulcers.

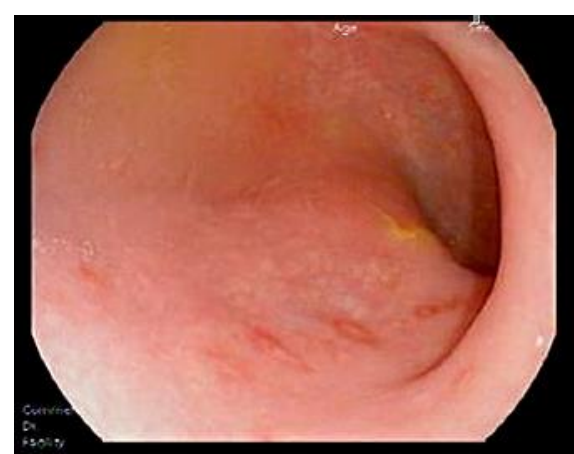

Fig. 6. Colonoscopy showing descending colon with multiple tiny aphthous ulcers at the recto-sigmoid junction.

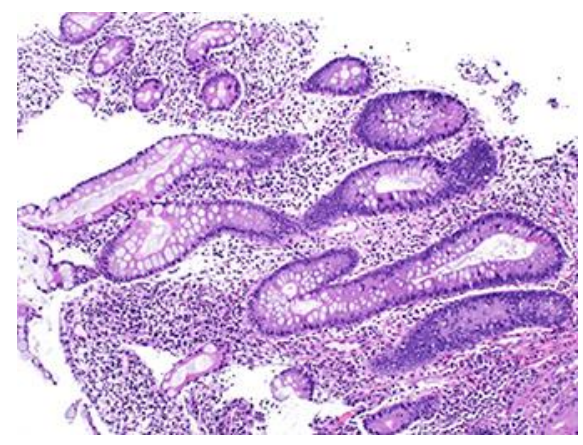

Fig. 7. Histopathology photograph depicting colonic mucosa with chronic changes in the form of crypts architectural distortion. The glands show irregularity and branching (hematoxylin and eosin stain 1,000). 


\section{Case Reports in Gastroenterology
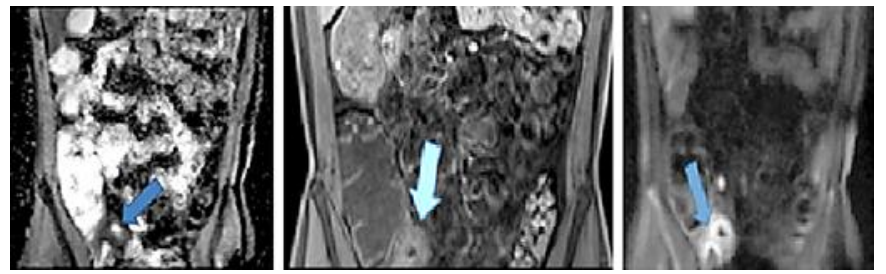

Fig. 8. MRI enteroclysis: the distal ileum, ileo-cecal junction, and cecal pole demonstrate mucosal thickening. Post contrast early enhancement and diffusion restriction is most prominently at the ileo-cecal junction. The distal ileal loop demonstrates engorgement of its mesenteric vessels representing comb sign. 